In our case, during the event, the MAC of sevoflurane was 1.5 whereas fentanyl $<2 \mu \mathrm{g} / \mathrm{kg}$ was administered 5 minutes earlier and the child was being ventilated adequately. However, within 2 minutes of administering the intubating dose of cisatracurium and prior to laryngoscopy and any neck or airway manipulation the child developed sudden severe bradycardia. The fall in HR was not gradual over a period of time, but sudden, severe, and sustained after administration of cisatracurium, which reverted only after atropine was administered. After excluding all other causes, anaphylactic or anaphylactoid reaction following cisatracurium appears to be the possible cause for sudden severe bradycardia in our case. Although we did not assess serum tryptase/plasma histamine levels or perform immunoglobulin-E (IgE) assay in this case to confirm the diagnosis of anaphylactic reaction, we suggest laboratory testing to confirm the diagnosis even if there is an isolated symptom, such as bradycardia, and making a note of this in the medical record of the patient for future.

In literature, there are few reports of anaphylactic reaction (bradycardia, hypotension, cutaneous flushing, and bronchospasm) after administration of cisatracurium. ${ }^{7}$ However, isolated bradycardia has not been described. Although cisatracurium has a safe cardiovascular profile, this case highlights a rare and serious complication and delivers a word of caution regarding its use, especially in pediatric patients.

\section{Funding}

None.

\section{Conflict of Interest}

None declared.

\section{References}

1 Judith AL, Hermanides J, Houweling LP, Quak JL, David RC. Bradycardia in children during general anaesthesia. In: Fransisco R, Marquez B. Cardiac Arrhythmias-New Considerations. 1st ed Rijeka Croatia: Intech; 2012:343-356

2 Lien CA, Belmont MR, Abalos A, et al. The cardiovascular effects and histamine-releasing properties of 51W89 in patients receiving nitrous oxide/opioid/barbiturate anesthesia. Anesthesiology 1995;82(5):1131-1138

3 Fastle RK, Roback MG. Pediatric rapid sequence intubation: incidence of reflex bradycardia and effects of pretreatment with atropine. Pediatr Emerg Care 2004;20(10):651-655

4 Keenan RL, Shapiro JH, Kane FR, Simpson PM. Bradycardia during anesthesia in infants. An epidemiologic study. Anesthesiology 1994;80(5):976-982

5 Kraemer FW, Stricker PA, Gurnaney HG, et al. Bradycardia during induction of anesthesia with sevoflurane in children with Down syndrome. Anesth Analg 2010;111(5):1259-1263

6 Pagel PS, Farber NE, Cerebral physiology and effect of anesthetic drugs. In: Miller RD, ed. Miller's Anesthesia. 8th ed. Virginia, VA: Elsevier Saunders; 2015:710-715

7 Clendenen SR, Harper JV, Wharen RE: Jr, Guarderas JC. Anaphylactic reaction after cisatracurium. Anesthesiology 1997;87(3):690-692

\title{
Clipping of Cerebral Aneurysm in a Patient with Coarctation of Aorta: Anesthetic Management
}

\author{
Summit Bloria' Neha Maheshwari ${ }^{1}$ Hemant Bhagat ${ }^{2}$
}

\footnotetext{
${ }^{1}$ Department of Anaesthesia, Postgraduate Institute of Medical Education and Research (PGIMER), Chandigarh, India

${ }^{2}$ Division of Neuroanaesthesia, Department of Anaesthesia and Intensive Care, Postgraduate Institute of Medical Education and Research (PGIMER), Chandigarh, India
}

J Neuroanaesthesiol Crit Care 2021;8:150-151.

We report perioperative management of a 45-year-old male patient with coarctation of aorta ( $\mathrm{CoA})$ posted for clipping of ruptured posterior inferior cerebellar artery (PICA) aneurysm. A 45-year-old male patient, a known hypertensive for

Published online

March 14, 2020
DOI https://doi.org/ 10.1055/s-0040-1701801 ISSN 2348-0548.
Address for correspondence Neha Maheshwari, MD, Department of Anaesthesia, Postgraduate Institute of Medical Education and Research (PGIMER), Sector-12, Chandigarh 160012, India (e-mail: nehadoc2705@gmail.com).

past 1 year, presented to this hospital with sudden onset of severe headache and drowsiness for 2 days. An urgent noncontrast computerized tomography (NCCT) head was done, which revealed intraventricular hemorrhage in third and

(C) 2020. Indian Society of Neuroanaesthesiology and Critical Care.

This is an open access article published by Thieme under the terms of the Creative Commons Attribution-NonDerivative-NonCommercial-License, permitting copying and reproduction so long as the original work is given appropriate credit. Contents may not be used for commercial purposes, or adapted, remixed, transformed or built upon. (https://creativecommons.org/licenses/by-nc-nd/4.0/).

Thieme Medical and Scientific Publishers Pvt. Ltd. A-12, 2nd Floor, Sector 2, Noida-201301 UP, India 
fourth ventricles. Digital subtraction angiography (DSA) via the femoral route was attempted to locate the site of bleed but could not be done as the DSA team had difficulty in negotiating the guidewire beyond the aortic isthmus. CT angiography was subsequently done and revealed shelf-like narrowing at aortic isthmus beyond the origin of subclavian artery, suggestive of $\mathrm{CoA}$ ( - Fig. 1). Cerebral CT angiography also revealed a ruptured right PICA aneurysm.

Transthoracic echocardiography in this patient revealed normal left systolic function with ejection fraction of 55 to $60 \%$. Considering the ruptured cerebral aneurysm to be an urgency and the fact that hemodynamic fluctuations might occur during correction of coarctation, cardiology team opined that the cerebral aneurysm be clipped in this patient prior to correction of coarctation. We subsequently reviewed the patient for clipping of aneurysm under general anesthesia, and he was accepted for anesthesia under high risk.

On the day of surgery, the patient was taken to operation theater and baseline monitors were attached. His left radial artery was cannulated under local anesthesia and arterial blood pressure (BP) was transduced, which was 211/99 mm Hg. Noninvasive BP was taken in the left calf and it was $128 / 76 \mathrm{~mm} \mathrm{Hg}$.

Our intraoperative aims were to prevent fluctuations in BP and prevention of ischemia below the coarctation of aorta. After a standard induction of anesthesia, an arterial cannula was placed in the left posterior tibial artery and was transduced to measure BP distal to the coarctation of aorta. Mean BP in the lower limb was maintained above $60 \mathrm{~mm} \mathrm{Hg}$ throughout the surgery ( - Fig. 2). Intraoperative urine output was adequate $(2 \mathrm{~mL} / \mathrm{kg} / \mathrm{h})$. Postoperatively, the patient was shifted to intensive care unit (ICU) for elective ventilation as it was a poor grade aneurysm (Hess and Hunt grade 4). In the ICU, monitoring of invasive BP in both left radial and left posterior tibial arteries was continued with the aim of maintaining a mean $\mathrm{BP}$ of $>60 \mathrm{~mm} \mathrm{Hg}$ in the lower limb. He was gradually weaned off and extubated the next day.

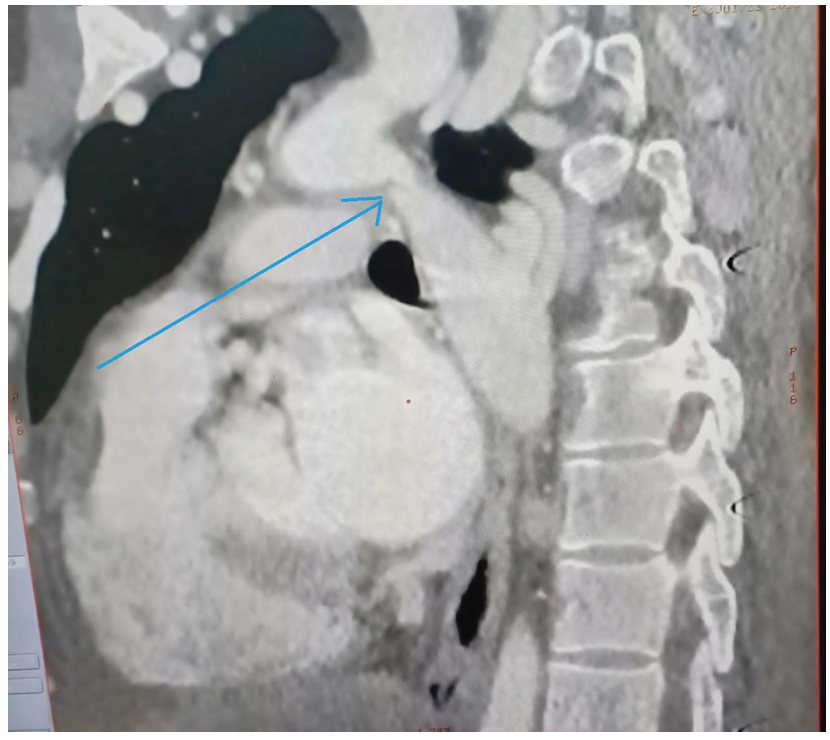

Fig. 1 CT angiography demonstrating coarctation of aorta. The arrow points toward the site of coarctation. CT, computed tomography.

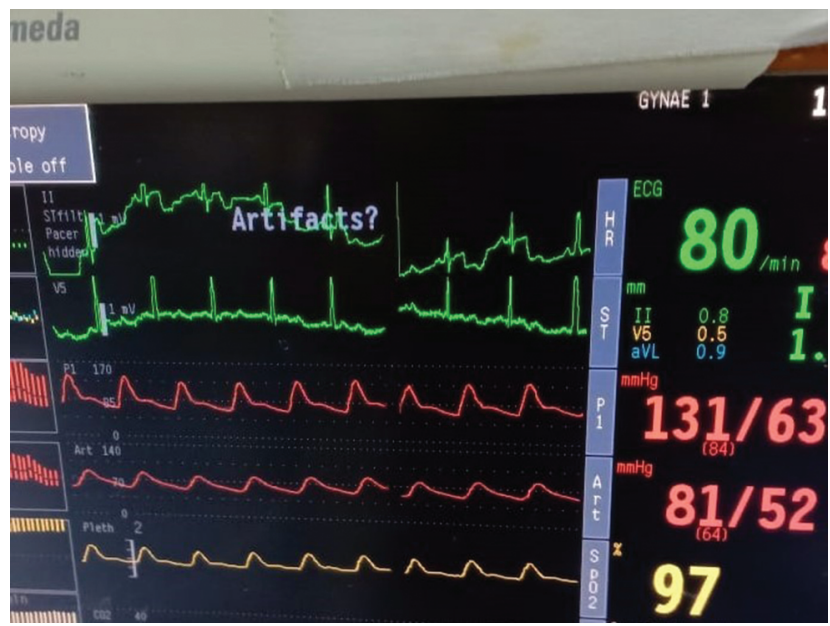

Fig. 2 Intraoperative monitoring of invasive BP in upper and lower limb. BP, blood pressure.

Eppinger had first described aortic coarctation complicated with intracranial aneurysm. ${ }^{1}$ In patients with $\mathrm{CoA}$, it has been suggested that the elevation of $\mathrm{BP}$ in the head, neck, and upper limbs, caused due to aortic constriction, predisposes to the development of intracranial aneurysm. Mercado et al discussed whether CoA or aneurysm should be first treated in these patients. They suggested that aneurysms should be first treated in the presence of an unnoticed CoA as they have a higher risk of rupture. ${ }^{2}$

Anesthesia management of these patients includes the following: (1) maintaining adequate perfusion distal to coarctation so as to prevent ischemia, and (2) preventing hypertension proximal to coarctation. With this aim, we used invasive BP monitoring in both upper and lower limbs in our patient and kept the mean BP above $60 \mathrm{~mm} \mathrm{Hg}$ in lower limbs. Recently, Paul et al had managed a case of CoA taken up for coiling of an intracranial aneurysm on similar lines. ${ }^{3}$ Azimee et al reported poor outcome in a patient of CoA taken up for intracranial aneurysm coiling when only radial artery pressures and urine output were used to guide BP management. ${ }^{4}$ They had also recommended the use of two invasive arterial lines while caring for these patients.

\section{Conflict of Interest}

None declared.

\section{References}

1 Eppinger H. Stenosis aortae congenita seu isthmus persistens. Vrtljschr Prakt Heilk 1871;112:31-67

2 Mercado R, López S, Cantú C, et al. Intracranial aneurysms associated with unsuspected aortic coarctation. J Neurosurg 2002;97(5):1221-1225

3 Paul S, Bloria SD, Bhagat H, Luthra A. Anesthetic management of a case of coarctation of aorta taken up for intracranial aneurysm coiling. J Neuroanaesthesiol Crit Care 2020;7(1):38-40

4 Azimee A, Chakravarty S, Anand S. Paraplegia in subarachnoid hemorrhage complicated with coarctation of aorta: an unusual complication. J Neurosurg Anesthesiol 2019;31(1):81-82 